\title{
Transferring, Translating and Transforming knowledge: The role of brokering in healthcare networks
}

\begin{abstract}
Purpose: This research examines how knowledge and information is managed within two care networks. We develop a conceptual framework drawing on the notion of brokering and the $3 \mathrm{~T}$ framework, which is used to describe the relative complexity of boundaries (referred to in the framework as syntactic, semantic, and pragmatic) as well as capabilities and processes required to exchange information within the network. Previous research on brokering has focused on healthcare managers and professionals this research extends to patients and caregivers. Understanding knowledge exchange and brokering practices in healthcare is critical to the delivery of effective services.
\end{abstract}

Design/methodology/approach: For this case research non-participant observation and experienced-based interviews were undertaken with healthcare professionals, patients, and caregivers within two care networks.

Findings: Our findings reveal brokering roles occupied by healthcare professionals, patients and caregivers support the transfer, translation and transformation of knowledge and information across functional and organisational boundaries. Enablers and disablers to brokering and the exchange of knowledge and information are also identified.

Research limitations/implications: The study is limited to two care networks for long term conditions within the UK. Further research opportunities exist to examine similar care networks that extend across professional and organisational boundaries.

Practical implications: This research informs healthcare professionals of the brokering capabilities that occur within networks and the enabling and disabling factors to managing knowledge across boundaries.

Originality: This paper provides a conceptual framework that categorises how increased levels of knowledge and information exchange and brokering practices are managed within care networks. 


\section{Introduction}

Nations such as the UK are looking for ways to redesign the delivery of care with a variety of managerial approaches being introduced (NHS Plan, 2019). Such plans often negatively affect those involved, be they staff, patients or caregivers, especially relating to deficiencies in information. Research charts efforts which have been made to address the impact on people, ranging from exploring institutional inter-relationships and their effect on roles (Spyridonidis and Currie, 2016), to the exploration of customer contact, flow and the degree of customisation (Wikner et al., 2017), which in healthcare has led to a growing campaign for the co-production and co-creation of services (Kaehne et al., 2018; Bovaird et al., 2019; Williams and Radnor, 2021). One of the drivers for customisation, or what is often termed patient-centred care, is the increasing levels of long-term complex multiple patient conditions adding to the difficulties faced by staff of integrating multiple sources of information and treatment initiatives.

The siloed characteristics of healthcare organisations often created by organisational structures (e.g. GP practices versus hospital clinics) and medical specialisation, which are reinforced by separate budgets and different financial systems, hamper, and even disable, communication. Such characteristics create the complexity inherent in healthcare systems and increasingly challenge the transfer of knowledge and information within and across healthcare networks and create the need for brokering. Against this testing background clinicians are still expected to draw knowledge from across the organisational boundaries to deliver patient care (Quartz-Topp et al, 2019). The resultant brokering activities are usually considered as additional costs rather than the necessary glue to support efficient and aligned services and care networks. For the purposes of this paper, we define a care network to include providers from healthcare (primary and secondary care) and other services required to support the patient.

Through exploring the delivery and receipt of care for two long-term chronic conditions we investigate how knowledge and information exchanges are managed. We know information gaps are often bridged by professionals (Currie and White, 2012; Waring et al., 2013) and we know anecdotally that patients and caregivers also broker gaps in healthcare processes, systems and services to ensure relevant information gets to the necessary healthcare professional(s). Currently, what is not well understood is the nature of this brokering role, the gaps brokered, and the brokering strategies used. Previously, brokering in healthcare typically has been explored from the perspective of professionals 
(e.g. Currie and White, 2012; Currie et al 2015). We build on this research to explore the brokering of information from multiple perspectives.

Brokers sometimes referred to as boundary spanners or occupying hybrid roles, are enablers that help to bridge the knowing-doing gap by acting as conduits for the transfer of resources including advice, social support and information (Moolenaar and Sleegers, 2015). Engaging in brokering activities requires both the motivation and ability to translate knowledge and information from one domain to another (Kaplan et al., 2017). Brokers can connect groups by engaging in "transferring, translating, and transforming" practices, what Carlile terms the 3T framework (2004, p. 915). For a broker, the challenge can be to transfer information to an actor who will accept, understand, and value that information (Burt, 2005), along with trust in the brokers and the systems used to transfer information (Platt et al., 2019). One way of dealing with that challenge is developing processes and procedures that support information and knowledge transfer across boundaries (Fernandez-Mateo 2007). Given the increase in hand-offs, which can be defined as transfer and acceptance of patient care responsibility achieved through effective communication (Collins, 2017) and as healthcare service delivery continues to be redesigned, we propose brokering is an essential role in the design and delivery of healthcare networks/services. Using Carlile's (2004) 3T categorisation framework this paper aims to understand the nature of the brokering roles and the knowledge boundaries within two chronic long-term condition healthcare networks by addressing the following research questions:

RQ1. What type of knowledge/information boundaries exist within two long-term chronic condition care networks?

RQ2. What roles do healthcare professionals, patients and caregivers play in brokering and managing the knowledge boundaries in the two care networks?

RQ3. What strategies are used to ensure brokering capability and sharing of knowledge supports the effective delivery of care?

Next, we acknowledge the importance of patient experience and involvement in the provision of healthcare, followed by a brief review of the brokering literature along with Carlile's (2004) 3T framework. The methodology, results and discussion are then 
provided. The paper concludes with a summary of the findings in relation to the research questions followed by the limitations of the study and areas of further research.

\section{Patient and caregivers' experiences and involvement}

Calls have been made repeatedly to engage and involve patients, caregivers, and the public in their healthcare and particularly for them to be centre of these discussions (Ocloo and Matthews, 2016). Patient and Public Involvement (PPI) is now a key part of healthcare reforms across Western economies (Tritter, 2009; Wait and Nolte, 2006), which advocates that patients and the public can make an important contribution to most stages of healthcare planning and delivery (Coulter and Ellins, 2006). Patients are reported to draw on a mix of illness experiential and biomedical knowledge (Pols, 2014), religious and cultural values, and 'common sense' to frame their ideas, conceptualise and understand their illness experiences (De-Graft Aikins, 2003). A recent study examining patient experience in unplanned hospital readmissions reported both positive and negative experiences of care with the former relating to supportive interactions with staff and the latter associated with suboptimal clinical aspects of their care (e.g. pain relief) (Considine et al., 2019). Issues relating to communication and information exchange were also raised, with some patients reporting they did not receive the information they needed because staff were too busy, or it was not delivered in a way that was not understandable (Considine et al., 2019). In the UK, there are many formal groups and forums associated with public and patient involvement (e.g., Involvement hub - NHS England, Community Health Councils - NHS Wales) which actively look to involve patients in the design and improvement of care. In this paper we are interested in the formal and informal roles of patients and caregivers that exist when involved in receiving, transferring, and managing information associated with their care.

\section{Brokering in healthcare}

Research highlights the benefits of being able to broker information between actors and across departments and organisations (often referred to as boundaries) in the treatment of patients (Kellogg, 2014; Broekhuis and Pieter van Donk, 2011). Brokers mobilise information and knowledge through developing collaborative resources, a critical role if value is to be harvested within and across networks (Soda et al, 2018). Within healthcare, professionals are increasingly "being forced to evaluate components across a range of 
different domains - bio-medical, organisational, psychological and social - all at work simultaneously" (Cohn et al., 2013, p.40). This necessitates the need to effectively move information quickly and precisely. Challenges to transferring information and knowledge include the silos, structures and rules which limit interaction across functional and organisational boundaries (Liverati, 2017, Aitken et al., 2020). Professional expertise and standards also hinder information movements due to lack of a common lexicon across task-specific language, institutional protocols, norms and work practices (Kellogg et al, 2006). Healthcare professionals usually operate autonomously due to specialisation (Meijboom et al., 2011) increasing the challenges faced by care systems in delivering an integrated care network that many patients need and assume exists. The separation of information systems is also reported as causing a division between professional groups (Karltun et al., 2020). Therefore, moving information amongst professionals and functions, in the treatment of patients, necessitates the bridging of the information gap from between domains to facilitate its transfer from one domain to another (Kaplan et al., 2017).

Bridging the interstices between healthcare professionals to overcome both the structural and task-based difficulties require brokers to "initiate, influence, manage, or facilitate interaction across (sic) boundaries" (Levy et al., 2019, p.426). Brokerage supports the movement of information and resources across siloes within networks. Through their connecting practices brokers can operate as conduits for the transfer of advice, social support, and information (Moolenaar and Sleegers, 2015). Bridging the gap allows the broker to create value where the value of the information presented resides in someone else accepting it, and not with its provider. The challenge for the broker is to transfer the information to an actor who will accept and value it (Burt, 2005). Presenting and framing ideas and concepts accurately and concisely to a diverse audience necessitates understanding their needs, capturing their attention, and gaining their support in accepting the information on offer (Soda et al., 2018). It is assumed the broker has a good understanding of the roles, professions, and organisations in which they are brokering, which suggests healthcare professionals are more likely to play this role. However, professional expertise and concerns with institutional arrangements related to indemnity and risk (Vargo and Lusch, 2017) make healthcare networks particularly challenging environments for brokers to engage actors within and across organisational boundaries to 
support the care network in the delivery of seamless patient treatment. This requires the facilitation of a discussion between professionals, to support the transformation of local knowledge into jointly produced knowledge which must supersede diverging interests for the benefit of the care network (Carlile, 2004). Consequently, boundaries blur between distinctive professional competencies in the pursuit of patient care (Liberati, 2017).

\section{Brokering within and across organisations}

Connections between professionals and functions are crucial to ensure an organisation operates effectively and achieves its objectives (Broekhuis and Pieter van Donk, 2011; Fernandes et al., 2018). Where interstices exist, the information flows required to make the organisation work effectively are disrupted at the boundaries between disciplines (Monge and Contractor, 2003). Bridging the gaps provides an opportunity for brokers to reduce the impact and disruption caused by delays to the flow of valuable information and knowledge in an organisation. By leveraging social capital from the connections between organisational actors to close information gaps brokers can perform an “intrapreneurial” role within an organisation (Heng and Loosemore, 2013). For example, intrapreneurial activities in the care sector have been reported in continuous improvement projects where 'lean champions' operate as brokers to support changes across functions (Eriksson, 2017). Working across different functions, within the same process, these 'lean champion' brokers transform the current knowledge of care actors through developing a common understanding across boundaries of best practices (Lindsay et al., 2020). Similarly, Quartz-Topp et al., (2019) examine how hospital managers design what they term hybrid forums, tools, and professional roles to facilitate the sharing of quality improvement (QI) knowledge, values, and practices with clinicians. The authors make a distinction between different types of knowledge (e.g., managerial QI and clinical QI) and report innovative hybrid tools, roles and forums that help to generate and integrate relevant QI knowledge that is acceptable to both managers and clinicians.

A broker's influence in an organisation is not only a function of their legitimate power but a function of their position between functions (Burt, 2005). "Central" brokers located at the intersection of information flows between parties command the most powerful positions while those on the periphery occupy the least powerful positions (Burt, 1992). 
These ideas can inform us of the role of healthcare staff and patients/caregivers might play as a conduit in the delivery and co-creation of healthcare services.

\section{T Framework}

We draw on Carlile's 3T framework (Carlile, 2004) to identity how the exchange of knowledge at a boundary is managed. Distinctions are made between three types of relational properties of knowledge at boundaries and how these impact on the movement of information and knowledge. The first is difference in knowledge which refers to a difference in the amount of knowledge accumulated (e.g. novice and expert) (Hinds, 1999). Within healthcare this could be exemplified by the difference in knowledge held by a first-year trainee nurse and a ward matron. This in turn creates differences in levels of experience, terminologies, tools, and incentives (Carlisle and Rebentisch, 2003). As the difference in the amount of domain-specific knowledge increases between actors, the amount of effort required to adequately share and assess each other's knowledge also increases.

The second knowledge difference at the boundary is dependence - without dependence, difference is of no consequence to the actors involved (Carlile, 2004). Dependence can be found in such activities as clinicians and managers co-authoring a patient safety and quality strategy. Knowledge can be different in kind and degree, which means managing dependencies requires the capacity to develop an adequate understanding and common knowledge as resources and tasks change. The third difference relates to how novel the circumstances are. This novelty could relate to actors being asked to share knowledge with others and to access knowledge from others. Common knowledge is a boundary object (Carlile, 2002) which actors use to communicate across domains. When novelty is present both the capacity and the ability of the actors to share a common knowledge becomes challenging and an important issue (Carlile, 2004). The greater the novelty the higher the level of relative complexity and effort required to manage the boundary. Actors can misrecognise something that is novel as being known (Levitt and March, 1988), or discard what is novel as being irrelevant (Perrow, 1994).

Carlile's (2004) integrated/3T framework, for managing knowledge across boundaries, draws on Shannon and Weaver's (1949) three levels of communication complexity - 
syntactic, semantic, and pragmatic. The most common phrase used to describe movement of knowledge in organisations is "knowledge transfer" (Argote, 1999). This information processing (also referred to as syntactic transfer) approach is the most dominant view in organisation design and forms the basis of most technology-based approaches to knowledge management, where the focus is on storage and retrieval of knowledge (Davenport and Prusak, 1998). This assumes there is sufficient stable conditions that support the development of common knowledge and lexicon; simply transferring knowledge can be problematic when novelty arises as it may be difficult to represent the differences and dependencies that are likely to be present due to the absence of a common understanding.

Movement from the syntactic to semantic boundary occurs when novelty makes some differences and dependencies unclear or some meanings ambiguous rendering knowledge difficult to transfer. This requires translating knowledge where mechanisms or roles are developed to help create 'shared meanings' and bridge the gap between actors different interpretations - these might include cross-functional teams, co-location and individuals to operate as brokers and translators (Hargadon and Sutton, 1997). Two critical abilities are required (Breidbach et al., 2013):

1. The ability to externalise knowledge to develop a common meaning - making tacit knowledge explicit is critical to the flow of information.

2. The ability to negotiate varying interests therefore developing a willingness for actors to alter knowledge and interests from their own domain.

Together they enable the broker to frame ideas and concepts contextually, accurately and concisely, in an audience-specific way, and present them through common meanings such that they are readily accepted (Soda et al., 2018).

The pragmatic boundary refers to situations where novelty results in different interests among actors that need to be resolved. This means that domain-specific knowledge and common knowledge will need to be transformed to effectively share and assess knowledge at the boundary. Transforming knowledge that can be shared and assessed requires substantial practical effort and actor willingness to enact common interests to facilitate sharing at the boundary (Carlile, 2004). The ability to influence other actors to 
develop a common interest in transforming knowledge is a critical capability when faced with increasing levels of novelty. Team working is one mechanism to help transform knowledge along with boundary objects such as drawings and other visuals (Carlile, 2002).

The 3T framework is helpful to categorise and show the relative complexity of a boundary (e.g. syntactic, semantic and pragmatic) and to identify the different types of capabilities (e.g. transfer, translate and transform) that exist for exchanging knowledge. Although the three types of boundaries are clearly defined, the transition where one ends, and another begins is not often easily identified by the actors involved. This lack of clarity creates mismatches between the type of boundary and the capability/process used to share knowledge. In this study, we employ the framework to understand the brokering of knowledge and information within and across boundaries of the two care networks.

\section{Conceptualisation of the 3T framework for care networks}

Drawing on Carlile's (2004) work this paper aims to examine how knowledge and information is transferred within a healthcare environment. We have identified from the broker and knowledge management literature important factors that need attention when transferring, translating, and transforming information where there are multiple actors within a care network. Figure 1 illustrates our knowledge boundary management framework based on the $3 \mathrm{~T}$ model. Relational factors identified from the literature that are likely to influence the management of information and knowledge across boundaries in a care network are social capital and ability to effect relationships, framing ideas and concepts to various actors and articulating the value of the information and encouraging others to engage.

Insert Figure 1 about here

\section{Methodology}

Case study research is acknowledged as a methodology and strategy of inquiry (Yin, 2014). It facilitates 'exploration of a bounded system through detailed, in depth data collection involving multiple sources of information and reports a case description and case-based themes' (Creswell, 2007 p. 73). Our research questions lend themselves to an exploratory approach and an inductive methodology to allow the building of theoretical 
insights (Yin, 2014). Case study research is designed to optimise understanding of the case rather than to generalize beyond it (Stake, 2005), although we envisage the insights into the nature and role of brokering will be relevant in other healthcare situations where patients frequently transition professional and organisational boundaries and particularly where these are not well-connected in relation to knowledge/information exchanges.

This single setting case research was conducted within the UK NHS healthcare system and focused on long term conditions (see Figure 2). The first sub case was chronic obstructive pulmonary disease (COPD), a long-term respiratory condition. The network (often termed a care pathway) covered providers and services in both primary care (GPs, community nursing) and secondary care (clinics, in-ward, emergency admissions). The second sub case was Huntington's Disease (HD), a progressive neurological condition caused by a defective gene. The services for this care network were mainly based in the community provided by two specialist multi-professional teams based in different areas of the UK. Figure 3 shows the key actors involved in each of the care networks.

Insert Figures 2 and 3 about here

Both the HD and COPD care networks rely on a variety of actors to work together to provide care to patients. These two networks were selected as both focus on long-term chronic conditions. For HD prevalence in 2010 was estimated to be 12.3 per 100,000 persons in the UK (Evans et al., 2013). For COPD prevalence is estimated to be 2000 per 100,000. This is for those patients that have been diagnosed with COPD in the UK (British Lung Foundation, 2020) it is estimated there are many more people living with COPD without a formal diagnosis. Regarding volume of patients, complexity of conditions and variation of need, requirements will be different for each network. Using two different care networks enables us to develop greater theoretical insights of knowledge exchange and the roles of those brokering networks and services.

Experienced-based semi-structured interviews were conducted with 45 healthcare professionals, patients and caregivers (see Table 1) from the two care networks, which included secondary (hospital) and primary (Specialist community nurses) care. Approval was obtained from the NHS Research Ethics Committee (IRAS 158439). All participants 
were provided with information sheets via email (staff) or at clinics or family groups (patients/caregivers). Informed consent was obtained from all participants prior to conducting the interviews. The inclusion and exclusion criteria for the selection of participants are shown in Table 2. Patient and caregiver participants were recruited via the senior team lead or physician for each of the care networks.

Participants were selected based on their knowledge and experience of either providing care or living with COPD or HD. This approach to sampling allowed us to deliberately include a range of key participants with access to important sources of knowledge and experience of the two care networks (May, 1995). Of the 23 patients invited to join the study 12 agreed and 8 caregivers participated. There were no withdrawals from the study. Twenty-eight staff participants were contacted directly either in person or by email, 25 agreed to participate in the study.

Non-participant observations were undertaken with the COPD and HD staff teams. For the COPD care network this involved observing three ward rounds ( 7.5 hours). Interactions between health professionals, patients and caregivers were observed along with sources of information relating to the condition. The HD care network involved the observation of three patient and caregivers support groups (6 hours). Research notes of the setting, experiences of the care pathway, and knowledge/information exchanges were compiled immediately after each observation and triangulated with the interview data.

\section{Insert Tables 1 and 2 about here}

The interviews with healthcare professionals were conducted at their place of work. In the case of patients and caregivers, the interviews were carried out at their homes. Interview guides were prepared for patients and caregivers (see Table 3) and staff participants (see Table 4), which explored the design of the network, experiences of those giving and receiving care, areas of good practice and possible improvements. The duration of the interviews was typically between 45 to 90 minutes. The interviews were transcribed verbatim with dialect (Gibbs, 2018) and manually coded and analysed using King's (2004) thematic framework. This template approach allows for the development of conceptual themes and clustering of these themes into broader groupings (Cassell and 
Symon, 2004). Template analysis requires a list of codes or a 'template' to be produced which represents themes identified in textual data (King, 1998). The initial area of enquiry for the main study was the design of care pathways (for further details see authors, 2017; 2020). Here we have used relevant parts of the data set that focused on brokering and information/knowledge exchange.

Insert Tables 3 and 4 about here

\section{Data and analysis}

Fully transcribed interviews and observational notes provided a rich set of data which were analysed through the construction of an initial template based upon two key signposts: the first was the main research topic for this paper, brokering in the context of knowledge exchange and information sharing. The second was the key themes that emerged from reading the first few transcripts. The development of themes was iterative given there were staff, patient and caregiver participants. The template reflects a hierarchical structure of a priori codes (e.g. knowledge sharing) which are then subdivided into lower order codes (e.g. availability of patient records/history). An extract from the coding template is shown in Figure 4. Once key themes were identified the order was decided post analysis. Illustrative examples are highlighted using direct quotes from the participants.

\section{Insert Figure 4 about here}

This paper reports only on the themes that emerged from the data specifically relating to the type of boundaries, the processes used to transfer information and knowledge, and roles defined as brokering which occurred within and across the two care networks. Other themes directly associated with improving the design of the patient pathway/network are outside the scope of this paper and have been previously reported (Authors, 2017; 2020). Much of this activity occurred at the interface of professional and organizational boundaries. Patients (and caregivers) were asked to describe their journeys prior to and since their diagnosis, which included explaining what had gone well and what could be improved. Healthcare professionals from both the community and acute providers were asked to share their understanding of the care network, how it works and their role within the network. Understanding and mapping the experiences of participants enabled us to 
identify how knowledge was exchanged and the information gaps in the network. These then enabled us to code and classify the activity in terms of knowledge and information sharing, the types of brokering undertaken and identifying boundary issues.

To enhance external validity, a combination of within case and cross case analyses was adopted (Yin, 2014). Within case analysis identified the brokering and knowledge exchange by each care network. For the cross-case analysis, similarities and differences across the two networks were identified. For internal validity, the results were presented to healthcare professionals and patient and caregiver support groups. Several steps were also taken to protect against bias and enhance the reliability of the findings, which included the triangulation of interview and observation data, two of the authors checking the coding of the data and the findings being reviewed by all authors.

\section{Findings}

From the analysis of the interview and observational data, it was evident healthcare professionals, patients and caregivers all occupy brokering roles in both care networks. Using the framework developed earlier (Figure 1), this paper identifies the gaps between actors and reports on the activities used by participants to transfer, translate and transform information across these interfaces. The results are presented in relation to the key themes identified from the template analysis.

\section{Information accuracy and availability}

Issues relating to the accuracy and availability of information were highlighted mainly by staff participants from both acute (hospital) and community settings. One of the examples given was trying to locate records if patients were not known to the hospital or were from out of the geographic area covered by the hospital. "So if they're [patient] not known, if they haven't come into hospital before, or they haven't come to a clinic ......., we have no history whatsoever. ... it would be too time-consuming for us to go, to speak to each of the primary care services to find out what's happened for that patient. So we rely on what the patient tells us." (COPD staff participant). The patient in this instance must translate their knowledge (semantic) of their condition in the absence of patient records. 
The availability of information was also problematic if these 'unknown' patients were admitted to the emergency department outside the hours of primary care services such as GP practices. In such cases patients and caregivers are asked to act as a conduit and provide as much detail of medical history and symptoms until other information can be located. If a patient arrives from a nursing home, it is more likely a caregiver will provide a care plan which helps to transfer important medical information across the acute and community organisational boundary.

Multi-disciplinary/professional teamworking helps to bridge some of the information. For example, when a patient is admitted onto a ward, then a pharmacist will help with medication history by checking what medication the patient or family bring into the hospital and by consulting the GP surgery. Such action provides a brokerage service through transferring information across the syntactic boundary. To improve the availability of information, one staff participant spoke of the development of a chart/ booklet for HD patients to help with this issue: “We're trying to establish sort of charts and sort of booklets with their (patients) medicines in, so in case they go to hospital and they've got all that information there for them and the families know as well... for some people, just a little notebook with everybody who's involved." (HD Staff participant). Such artefacts help to create a shared meaning to support knowledge and information transfer across the syntactic boundary.

Much of the interview data referred to transferring information when not easily located within the care network. However, in the case of HD patients and caregivers the transferring of data may also extend to translating the information if clinicians were not familiar with the condition. Requiring the patient/caregiver to operate as a broker across the semantic boundary to translate their knowledge in a shared meaning with the care provider. This may occur when a HD patient is admitted to an emergency department and access to medical records, or the specialist HD team are not available.

\section{Knowledge of condition}

The level of knowledge of professions and patients/caregivers varied depending on the condition. For COPD the knowledge resided more with the healthcare professional 
participants than the patients. Several of the patient participants spoke about requiring further information about their condition, with some locating information from online sources. One participant noted the lack of information available on wards, which as an inpatient, he had the time to read and felt would enable him to further his knowledge and management of his condition. Conversely for HD it was the patients and caregivers who were likely to have more knowledge of the condition than professionals working outside of specialist HD teams. Through transferring and translating this experiential knowledge patients/caregivers attempt to bridge the gap in the care network therefore retaining the value co-created in previous treatment occasions. However, as noted by one participant this approach is only successful if the patient/caregiver can engage and communicate with the healthcare professional to make her/him accept the knowledge being offered. The novelty of disease often leads to patients translating knowledge for the healthcare provider.

Several patient and caregiver participants spoke about the difficulty of getting a diagnosis both for HD and COPD. One patient spoke about the struggles of communicating with the GP to get a referral to a HD clinic. A caregiver recalled a discussion with a GP stating “you haven't got HD, you've got no symptoms and here's some paperwork... He (the patient) came away, he read the information, he went back again and saw Dr... who referred him for the test". The caregiver spoke about the importance of being able to share the knowledge and information in a way that assisted the GP to overcome a pragmatic boundary by understanding the early signs of what for many would be a 'novel' condition.

Another caregiver spoke of the late diagnosis of her husband's HD. 'It wasn't picked up, I knew there was something wrong, so eventually I wrote down the symptoms and we took the letter to the doctor". The caregiver acted as a broker to engage and raise the interest of the doctor to assist them at the pragmatic boundary. Both situations may relate to assuming there is sufficient common knowledge by all actors involved (professionals, patients, and caregivers) for knowledge and information to be transferred. As noted earlier, this can be problematic when novelty arises in situations where the healthcare professional's awareness or knowledge of HD is limited and/or where patients and caregivers experience difficulties in communicating the relevant symptoms - hence the 
difficulties of being able to represent the differences and dependencies which are likely to be present due to the absence of a common understanding. For HD the results indicate that the patient/caregiver may need the brokering capabilities of creating sufficient interest for the care provider to engage them in transforming their knowledge at a pragmatic boundary.

COPD patients also spoke of the difficulties of getting referrals to clinics. "I saw several doctors before I was eventually referred to Dr .... clinic, despite going to the surgery several times with the same issues". It was unclear from the participants whether the issues occurred due to not explaining the symptoms in sufficient detail or that the healthcare professional was unaware of the condition. Several of the COPD participants again referred to the internet to help them understand the symptoms and one suggested this had helped her to articulate her condition in "a better and more understandable way". For COPD patients the development of their common knowledge and lexicon, through codified sources, can assist them in brokering the exchange of knowledge with care providers at the syntactic boundary. It is possible in such situations where the novelty of the condition is misrecognised as being already known or discarded as irrelevant. This challenge is apparent with conditions such as HD where care professionals may not have the knowledge or interest in assessing the patient from that novel perspective.

\section{Information sharing}

Several of the staff participants from both networks spoke about the importance of good governance and protocols being in place to ensure appropriate sharing of information. Whereas some patient participants, although presumed information would be shared with care providers, were less clear how this might occur. For example, one inpatient COPD participant spoke of the various members of staff he had seen since being admitted to hospital and his assumption that information would be shared with his GP: "So I would imagine there's going to be some sort of liaison with my GP". However, he was unclear how this information would be provided and when this might happen.

Another patient participant mentioned the need for more information about her condition “... just knowing isn't it?” but unclear where or how to access this. As noted previously, 
several of the patient participants mentioned they had consulted the internet to find more information about their condition or services in the area. Such information and access to services is important for the experiential understanding of the condition and the development of common language to be shared with care providers, with the caveat such information is obtained from reliable sources.

Specialist healthcare professionals also occupied a brokering role within both networks. These can be in the hospital (respiratory) or in the community (respiratory and HD) and regularly 'inreach' or 'outreach' to services to bridge the gap between acute and community care and/or health and social care. For example, one COPD staff participant explained, "If the patient is not known to us on the ward, we contact the community respiratory team." The common knowledge and lexicon supported the sharing of knowledge and information across the syntactic boundary. Similarly, within the HD network an example of brokering information with social workers was given: "I was just asking for some information on what nursing homes might be suitable for somebody, so I can email that back," HD staff participant. This was further illustrated by participants developing their own systems to broker information flows across a network of care providers: “I've got a document I keep... that's got all the useful contacts I've ever run into along the last ten years.. so all the CCGs (Clinical Commissioning Groups) and CHC (Continuing Healthcare) nurses that I've ever had anything to do with... they will be different depending on the area, " HD staff participant.

\section{Discussion}

Our findings uncovered that information accuracy, availability and sharing as well as knowledge of the condition are important issues facing actors across interfaces. Revealing the different brokering roles occupied by healthcare professionals, patients and caregivers which support the transfer, translation and transformation of knowledge and information across functional and organisational boundaries. Table 5 summarises the results and key themes as well as the boundary issues faced by actors, the knowledge boundaries that exist and the broker capabilities used to address them. Staff, patient, and caregiver participants were found to engage in all three brokering practices - transferring, translating and transforming information. 
Insert Table 5 about here

Participants shared many examples of syntactic boundaries where they needed to transfer information. However, information accuracy and availability were identified mainly by care staff participants as being problematic within both networks. It was evident from the COPD network that transferring information was crucial as patients often cross organisational boundaries for their care (e.g. from community to secondary care). In the case of the HD network, given the 'novelty' of the HD condition common lexicons to support the transfer of information were often not sufficient to represent the differences (Carlile, 2004). Therefore, information translation and transformation were more prominent among the HD team and caregivers. As Carlile (2004) notes while a common lexicon is necessary, it is not always a sufficient type of common knowledge to share and assess a domain (in this case which requires specific knowledge). Closing the knowingdoing gap is dependent on actors being able to understand and value the relevance of the knowledge.

Analysis of the HD network data provided examples of where knowledge of the patient's condition was transformed by the family when interacting with services that had limited or no knowledge of HD (e.g. hospital or GP practice). This reduced the novelty of the condition for healthcare professionals with limited or no experience of the condition, through developing a brokering mechanism that provides a basis for shared meanings across knowledge boundaries. The staff participants from the HD specialist community teams provided examples of transforming information to enable their patients and caregivers to interact and access public services such as housing, benefits, and transport.

Information sharing across organisations is one of the tenants of partnership working that is reported to lag general partnership working (Richardson and Asthana, 2006). One issue raised by several of the participants related to the structures and protocols which can hinder embedding knowledge and interaction across organisational and functional boundaries for healthcare professionals (Kellogg et al, 2006) and therefore patient and caregiver involvement and knowledge transfer are treated with caution. This caution is likely to be heightened with the rarity of the condition. Yet, as noted here, the patients/caregivers are more likely to occupy the (unpaid) role of the broker and share 
information and knowledge particularly at the pragmatic boundary to assist care providers that are less familiar with the condition. However, the challenge of being able to communicate the information in such a way that it is received and valued by the receiver remains.

Issues around information sharing can be heightened due to poorly integrated systems where information is not transferred across the organisational boundaries e.g. primary and secondary care. Other knowledge boundaries exist due to the lack of or incompleteness of common lexicons to translate the information into common knowledge e.g. discharge letter, in other words the knowledge is not fully embedded within the local systems.

Table 6 develops our understanding of knowledge boundary management by providing examples of relational knowledge types and the main issues experienced by participants from both networks due to differences in knowledge between actors, dependence related challenges and the impact of increasing novelty. All three types of relational knowledge types were found to exist in both care networks creating boundaries between actors. The effectiveness of the brokering practices was influenced by language (ability to translate), 'power' relationships (ability to be heard/respected) and being able to garner the interests of other actors to create and assess new or novel knowledge.

Insert Table 6 about here

Carlile (2004) argues as the novelty increases in relation to the information the greater need for information to be transformed. The HD network provides examples of where healthcare professionals frequently act on behalf of their patients and families to broker the knowledge and information boundary between health and other services. The rarity of the HD increases the novelty of the information and highlights the need for participatory and relational nature of the actor's role. Previous research has shown that actors can misrecognise novelty as something that is already known (Martins and Kambil, 1999) or discard what is novel as irrelevant (Perrow, 1994). Such situations might arise where the patient/caregiver's experiential knowledge of the condition is not acknowledged. Or when a specialised team does not recognise others in the network might be less familiar with the condition and need to have additional information or develop more knowledge to ensure what is novel about the condition is not disregarded 
as being irrelevant. Several of the staff participants raised the need for stability of the team membership which enables relationships to be established both with patients, caregivers, and other services. Participants believed this stability enabled more effective bridging of professional, functional and organisational boundaries.

In this study, the need for brokering occurred within both COPD and HD networks at particular service intersections:

- Between patients and caregivers;

- Between patient/caregiver and health and social care professionals;

- Between specialist healthcare professionals and other health and social care professionals;

- Between specialist healthcare professionals, patients/caregivers and other public services.

Actors actively operate as brokers to bridge knowledge and information gaps through developing workarounds for information flow issues or implementing mechanisms that support the translation or transformation of knowledge at boundaries. For specialist healthcare professionals operating at intersections within their own organisations (e.g. respiratory specialist nurse brokering between the respiratory ward and Accident and Emergency Departments) these brokering activities can be described as intrapreneurial. With the specialists brokering the translation of knowledge on current best practices for other care actors.

Entrepreneurial roles were identified for example through the HD team brokering practices that close gaps across organisational boundaries through transferring, translating and transforming knowledge to support colleagues in accepting the value of the information that is being shared. Therefore, retaining and enhancing the value of knowledge that has been co-created within the care network. Those occupying these roles have the social capital gained from these relationships (Brass, 2003) to influence and support the flow of information within the network and add value to the patient experience (Burt 2005; Currie and White, 2012).

Previous research on brokering has focused largely on professional and managerial roles (Currie et al., 2015; Currie and White, 2012; Quartz-Topp et al., 2019). Here we start to 
identify how patients and caregivers address and bridge the information accuracy, availability and sharing as well as knowledge of the condition gaps that often occur between professionals and different organisations within the care network. This is a capability that has been largely anecdotal until now. A role we also describe as entrepreneurial, as patients ensure information about their condition is transferred/translated/transformed to relevant professionals within the care network.

These entrepreneurial roles of patients and caregivers were emergent and not part of formal expert patient programmes, which are designed to improve patient's skills and knowledge of their disease (Griffiths et al., 2007). Brokering the transfer of knowledge between care and other professionals can be challenging because not all patients and caregivers have the social capital to enact such roles, to address information and knowledge gaps, particularly when required to interact with institutional protocols and negotiate an information/knowledge system which is often poorly integrated. They also need to be able to work with task specific lexicons and practices to localise knowledge (Carlile, 2002). Recognising these potential obstacles has led to the development of brokering mechanisms, by specialist healthcare professionals, on behalf of HD patients which support the translation and transformation of their condition.

Interestingly none of the participants described or recognised their experiences as bridging gaps in the provision of knowledge or receipt of care. The brokering capabilities were largely about connecting actors within the system to aid the flow of information, knowledge and value, which then aids patient flow and improves patient experience. However, what is not clear from this research is the action taken by organisations to ensure either the brokering role is formally recognised, or steps are taken to bridge the knowledge/information gaps occupied by the broker. Overlooking the brokering activity can potentially introduce vulnerability into the network.

As a result of this research, we have identified several enabling and disabling factors (see Figure 5) that will impact the capability of the broker and how knowledge/information is managed and embedded within and across boundaries. Identifying these factors provides an opportunity for healthcare networks to develop strategies to ensure equality of support given to patients. These insights enable us to further develop our knowledge boundary 
management framework presented earlier in the paper. Enabling factors associated with broker capability to transfer information at syntactic boundary include having the appropriate support in place for patients/caregivers to be able to present information in way that can be heard and received by other actors. For the semantic boundary, an enabling factor is the ability to translate information so that it is valued by other actors. Enablers for the pragmatic boundaries focus on the transforming information to legitimise the 'informal' role and power of brokers operating at and across boundaries. Disabling factors related to broker capability can be identified depending on the complexity of the boundary. For example, patients/caregivers' limited knowledge of their condition could inhibit the transfer (syntactic) of information to other actors. The translation (semantic) of information could be hampered by external factors such as organisational structures and systems. Whereas the transforming (pragmatic) of information could be limited by actors' knowledge and exposure to rare diseases/conditions such as HD.

Enabling factors relating to the relational property of knowledge is the use of common lexicons to help brokers to understand and frame their knowledge to transfer to other actors. Specialist teams are also seen as enablers to translating and transforming information for various actors to establish effective and collaborative relationships across the network - in the case of the HD network this was achieved by the specialist team developing their own register of contacts. The inhibiting factors of the relational property of knowledge included poorly integrated systems, silo working and resource constraints to support the development of collaborative partnerships. It is here that we suggest focus needs to be on the development of appropriate strategies and institutional policies to support the enablers and reduce or address the disablers.

Insert Figure 5 about here

\section{Conclusion}

This paper examines the experiences of healthcare professionals, patients and caregivers occupying a brokering role within designated long-term condition healthcare networks. Drawing on Carlile's (2004) 3T framework and the concept of brokering, this research provides insight to the how and why brokering occurs. This research considers three questions, the first being the nature of the information boundaries that exist within two healthcare networks. Using the knowledge boundary management framework (Figure 1) 
the three knowledge boundary types (semantic, syntactic and pragmatic) were identified across the two care networks examined. Our HD case illustrates the differences and dependencies that exist when the novelty of knowledge increases, which in this case was due to the rarity of the condition. Brokers needed to not only transfer information but also translate and transform for those less familiar with the condition. Such activity requires HD patients and caregivers to build a knowledge base of the condition to enable them to fulfil this role and level of exchange, which may also create inequalities between people with different social capital.

Our second enquiry was the type of brokering roles occupied by healthcare professionals, patients, and caregivers. The examples provided by the participants suggested most of the brokering activity was connecting poorly aligned organisations and functions. Building on the brokering activity, knowledge transfer, translation and transformation were all evident from the analysis of the data. Localising and embedding knowledge in practice is often hampered by organisation structures and systems. It is also evident that some of the brokering roles are informal and emergent particularly those associated with patients and caregivers.

The final question considered the strategies employed to ensure information/knowledge flows to support the effective delivery of care. From our in-case and cross-case analyses we found differences in knowledge levels, dependence among actors and novelty of condition/ information are likely to influence the strategies required. For the COPD network the care professionals are seeing many cases against which (over and above professional protocols) influences their expectations about the most likely route/pathway the patient will experience. However, patients will only be familiar with their own condition and therefore may not know how to access and/or transfer this knowledge to a common lexicon. Instead moving to other forms of information which are accessible but not necessarily reliable. Therefore, for the more novel/rare conditions there is a greater need for knowledge translation and transformation strategies.

Silo working (which may be interpreted as professional boundaries) will also impact on the sharing of information and knowledge and strategies are required by actors to ensure transfer, translation and transformation occurs. The constraint surrounding the 'freedom' 
to transfer, translate, transform is assumed in the framework but in practice is actively constrained (legal/professional) in this setting and more likely to be constrained elsewhere given changes in personal data legislation. The owner of the data is the professional/organisation, yet it is the patient/caregiver who is often the conduit and is therefore a key actor for looking at knowledge and information with the individual as the enabler. Similarly, the movement of data is often constrained by the lack of IT connectivity which in the absence of brokering could lead to poor service delivery.

This case research has identified the importance of brokering capability and knowledge/information exchange within the delivery of care for two long-term conditions. The results are important for healthcare organisations as without brokering healthcare professionals and their patients would face the challenges of longer hospital stays, greater pressure on resources and equipment and increases in non-value-added activities due to delays in information transfer and decision-making. Further research is needed to understand the transition between the different types of boundaries and to assess how similar or dissimilar the knowing-doing gap is within dissemination and implementation research.

Although there is a long history of and widespread support for patient and public involvement, considerable barriers still exist (Ocloo et al., 2021). This research provides an important starting point for understanding the enabling role and capabilities of patients and caregivers in brokering knowledge and their important contribution to the management of information flows within their care networks. Recognition of such patient and public involvement activity needs to be carefully managed and valued if its full potential is to be realised. This research supports the call for better support, clarity of roles and expectations and the provision of knowledge, clear information and communication which will all positively impact on patient and caregiver involvement (Ocloo et al., 2021). Organisational strategies such as creating patient stories and holding 'listening events' to enable patients and caregivers to share their stores of service use and brokering activity would serve to inform and educate other actors within the network (Condon, 2019). This current conceptual framework is mainly predicated on equal capability across all actors. Barriers to involvement such as illness, which is often age related, low literacy, communication, or language difficulties (Ocloo et al., 2021) need further consideration. 
Further research is required to understand what strategies need to be in place to support those less able (cognitively, educationally) to occupy this role and where advocacy can assist in the provision of treatment equality.

Often brokering roles are emergent, unpaid and operate outside formal programmes such as patient expert programmes. The challenge for healthcare professionals is to identify who is undertaking such activity and the recognition of varying levels of professionalism and maturity within such roles. There is a need to understand where and when in the network brokering might occur, by whom and for whom.

This single case study is limited by the small sample of two care networks of chronic long-term conditions in the UK and therefore generalising results beyond what is reported here is limited (Stake, 2005). However, this case provides interesting and important information about the setting of two chronic condition care networks (Gibbs et al., 2007). It is likely chronic condition services in other geographical areas are arranged in similar ways with cross professional and organisational boundaries. Such care settings would enable the further testing of the conceptual framework provided. Other areas of enquiry should focus on developing a greater understanding of the roles of social capital, legitimacy and power held by the broker, along with the value of brokering by various actors, and the cost of brokering.

Here we have started to investigate the role of patients and caregivers in brokering information and knowledge within a care network. Currently, this is a role that is invisible, unpaid, and not formally recognised within the realms of patient and public involvement. Further research needs to formally recognise and build on these exchanges to enhance person-centred care. Similarly, understanding the impact of information/knowledge brokerage on patient outcomes is an important area for healthcare organisations and care networks to consider (Heng and Loosemore, 2013). Brokering as identified in this study is dependent on the capability and availability of the various actors, which presents issues of equality and risks of suboptimal pathways to care.

This paper provides a novel extension of the 3T framework (Carlile, 2004) for managing knowledge across boundaries. Importantly, we move the $3 \mathrm{~T}$ framework from a 
categorisation tool to a knowledge boundary management conceptual framework. In addition, we have identified enabling and disabling factors that could be used to inform the development of strategies that need to be in place to enhance the patient care role in brokering. As such, this paper furthers our understanding of the brokering capabilities needed to manage knowledge and information and provides a basis for future research, as well as guidance for healthcare professionals facing increasing handoffs and more complex conditions.

\section{References}

Aitken, J., Esain, A and Williams, S (2020), “Management of complexity in the care ecosystem”. Supply Chain Management: An International Journal, Vol. 26, No. 4, pp. 481-494. Doi.org/10.1108/SCM05-2020-0207.

Argote, L. (1999), Organisational learning: Creating, retaining and transferring knowledge. Norwell, Kluwer, MA.

Berry, L. and Bendapudi, N. (2007), "Health Care: A fertile field for service research", Journal of Service Research, Vol. 10, No. 2, pp 111-122.

Bovaird, T. Flemig, S. Loeffler, E. and Osborne, S. (2019), "How far have we come with co-production and what's next?" Public Money \& Management, Vol. 39, No. 4, pp. 229-232.

Brass, D. (2003), “A social network perspective on human resources management”, in Cross, R. Parker, A. and L. Sasson. (Ed.s) Networks in the Knowledge Economy, Oxford University Press, Oxford, UK.

Breidbach, C.F., Smith, P. and Callagher, L. (2013), “Advancing innovation in professional service firms: Insights from the service-dominant logic", Service Science, Vol. 5, No. 3, pp.263-275.

British Lung Foundation (2019), Chronic obstructive pulmonary disease (COPD) statistics. British Lung Foundation, London.

Broekhuis, M. and Pieter van Donk, D. (2011), “Coordination of physicians' operational activities: a contingency perspective," International Journal of Operations \& Production Management, Vol. 31, pp. 251-273.

Burt, R.S. (1992), Structural Holes: The social structure of competition, Harvard University Press, Cambridge, MA.

Burt, R.S. (2005), Brokerage and closure: An introduction to social capital, Open University Press, Oxford, UK.

Carlile, P. (2002). “A pragmatic view of knowledge and boundaries: boundary objects in new product development", Organisation Science, Vol. 13, pp. 442-445.

Carlile, P. (2004). “Transferring, translating and transforming: An integrative framework for managing knowledge across boundaries.” Organization Science, Vol. 15, No. 5, pp. 555-568.

Cohn, S., M. Clinch, C. Bunn, and Stronge, P. (2013), "Entangled Complexity: Why Complex Interventions are Just not Complicated Enough," Journal of Health Services Research and Policy, Vol. 18, No. 1, pp 40-43. doi:10.1258/jhsrp.2012.012036.

Collins, R. (2017), Hand-off communication: The weak link in healthcare, available at 
https://www.beckershospitalreview.com/hospital-management-administration/hand-offcommunication-the-weak-link-in-healthcare.html (accessed 20 December 2020).

Condon, L. (2019). "How patient stories can improve health services around the world", Health Expectations: An international journal of public participation in Health care and health policy, Vol. 22, No. 5, pp. 837.

Considine, J. Berry, D. Sprogis, S. Newnham, E. Fox, K. Darzins, P. Rawson, H and Street, M. (2019). "Understanding the patient experience of early unplanned hospital readmission following acute care discharge: a qualitative descriptive study", BMJ Open, e034728. doi:10.1136/bmjopen-2019-034728

Coulter, A. and Ellins, J. (2006), Patient focused interventions: a review of the evidence, The Health Foundation, London.

Creswell, J. (2007), Qualitative Inquiry \& Research Design choosing among five approaches (2nd Ed.), Sage Publications Ltd, London.

Currie, G., Burgess, N. and Hayton, J. (2015), "HR practices and knowledge brokering by hybrid middle managers in hospital settings: the influence of professional hierarchy", Human Resource Management, Vol. 54, No. 4, pp. 793-812.

Currie, G. and White, L. (2012), "Inter-professional barriers and knowledge brokering in an organisational context: the case of healthcare, Organisation Studies, Vol. 33, No. 10, pp. 1333-1361.

Davenport, T. and Prusak, L. (1998), Working knowledge, Harvard Business School Press, Boston.

De-Graft Aikins, A. (2003), "Living with diabetes in rural and urban Ghana: A critical social psychological examination of illness action and scope for intervention", Journal of Health Psychology Vol. 8, No. 5, pp. 557-572.

Eriksson, N.. (2017). "Hospital Management from a High Reliability Organizational Change Perspective: A Swedish Case on Lean and Six Sigma." International Journal of Public Sector Management, Vol.30, No1, pp 67-84.

Evans, S. Douglas, I. Rawlins, M. Wexler, N. Tabrizi, S. and Smeeth, L. (2013). "Prevalence of adult Huntington's disease in the UK based on diagnoses recorded in general practice records", Journal of Neurology, Neurosurgery \& Psychiatry, Vol, 84, No. 10, pp. 1156-1160.

Fernandes, A., Spring, M. and. Tarafdar, M. (2018), "Coordination in temporary organizations". International Journal of Operations \& Production Management, Vol. 38, pp+.1340-1367.

Fernandez-Mateo, I. (2007), "Who pays the prices of brokerage? Transferring constraint through price setting in the staffing sector," American Sociological Review, Vol. 72, No. 2, pp. 291-317.

Gibbs, G. (2018). Analyzing Qualitative Data, Sage Publications Ltd., London.

Gibbs, L. Kealy, M. Willis, K. Green, J. Welch, N. and Daly, J. (2007). "What have sampling and data collection got to do with good qualitative research?" Australian and New Zealand Journal of Public Health, Vol. 31, No. 6, pp. 540-544.

Griffiths, C. Foster, G. Ramsay, J. Eldridge, S. and Taylor, S. (2007). "How effective are expert patient (lay led) education programmes for chronic disease?" BMJ, Vol. 334, pp. 1254-1256.

Hargadon, A. and Sutton, R. (1997), "Technology brokering and innovation in a product development firm”, Administrative Science Quarterly, Vol. 42, pp. 716-749.

Heng, H. and M. Loosemore, (2013), "Structural holes in hospital organisations: Facilities managers as 
intrapreneruial brokers in the tertiary health sector". Engineering, construction and architectural management, Vol. 20, No. 5, pp. 474-487.

Hinds, P. (1999), "The curse of expertise: The effects of expertise and de-biasing methods on predictions of novice performance," Journal of Experimental Psychology, Vol. 5, pp. 205-221.

Kaplan, S., Milde, J. and Cowan, R.S., (2017), "Symbiont practices in boundary spanning: Bridging the cognitive and political divides in interdisciplinary research," Academy of Management Journal, Vol, 60, No. 4, pp.1387-1414.

Kaehne, A. Beacham, A. and Feather, J. (2018), "Co-production in integrated health and social care programmes: a pragmatic model", Journal of Integrated Care, Vol.26, No. 1, pp. 87-96.

Karltun, A. Sanne, J. Aase, K. Anderson, J. Fernandes, A. Fulop, N. Hoglund, P. Andersson-Gare, B., (2020). "Knowledge management infrastructure to support quality improvement: A qualitative study of maternity services in four European hospitals", Health Policy, Vol. 124, pp. 205-215.

Kellogg, K. Orlikowski, J and Yates, J. (2006), "Life in the trading zone: Structuring coordination across boundaries in postbureaucratic organisations", Organisation Science, Vol. 17, No. 1, pp 22-44.

Kellogg, K. (2014), "Brokerage professions and implementing reform in an age of experts, American Sociological Review, Vol. 79 No. 5, pp. 912-941.

King, N. (1998), Template Analysis in G. Symon, \& Cassell, C. (Eds.) Qualitative Methods and Analysis in Organisational Research, Sage Publications Ltd., London.

King, N., (2004), Using templates in the thematic analysis of text, in C. Cassell, \& G. Symon, (Eds.), Essential Guide to Qualitative Methods in Organisational Research, Sage Publications Ltd., London.

Levitt, B. and March, J. (1988), Organisational learning, In Scott, W. and Blake, J. (eds) Annual Review of Sociology, Annual Reviews, Palo, Alto. CA, pp 219-340.

Levy, O., Lee, H.J., Jonsen, K. and M.A. Peiperl, (2019), Transcultural brokerage: The role of cosmopolitans in bridging structural and cultural holes, Journal of Management, Vol. 45, No. 2, pp.417-450.

Lindsay, C.F., Kumar, M. and. Juleff, L. (2020). "Operationalising Lean in Healthcare: The Impact of Professionalism." Production Planning and Control Vol. 31, No. 8, pp.29-43.

Liverati, E.G. (2017), "Separating, replacing, intersecting: The influence of context on the construction of the medical-nursing boundary," Social Science \& Medicine, Vol. 172, pp.135-143.

Martins, L. and Kambil, A. (1999), "Looking back and thinking ahead: Effects of prior success on managers' interpretations of new information technologies". Academy of Management Journal, Vol. 42, pp. 652-661.

May, N. (1995). "Qualitative research: Rigour and qualitative research", BMJ, Vol. 311, p. 109.

Monge, P. and N. Contactor (2003), Theories of communication networks, Oxford University Press, Oxford, UK.

Moolenaar, N.M. and Sleegers, P.J. (2015), “The networked principal: Examining principals' social relationships and transformational leadership in school and district networks." Journal of Educational Administration, Vol. 53, No. 1, pp. 8-39.

NHS 10-year plan (2019), The NHS 10-year plan: how should the extra funding be spent? Department of Health, London, UK. 
Ocloo, J. and Matthews, R. (2016), "From tokenism to empowerment: progressing patient and public involvement in healthcare improvement”, BMJ Quality and Safety, Vol. 2, pp.626-632.

Ocloo, J. Garfield, S. Franklin, B.D. and Dawson, S. (2021). "Exploring the theory, barriers and enablers for patient and public involvement across health, social care and patient safety: a systematic review of reviews", Health Research Policy and Systems, Vol. 19, No. 8. https://doi.org/10.1186/s12961-02000644-3

Perrow, C. (1994), “Accidents in high risk systems”, Technical Studies, Vol. 1, pp. 1-38.

Platt, J. Raj, M. and Kardia, S. (2019), “The public's trust and information brokers in healthcare, public health and research", Journal of Health Organisation and Management, Vol. 33, No. 7/8, pp. 929848.

Pols, J. (2014), “Knowing patients: Turning patient knowledge into science”. Science Technology \& Human Values, Vol. 39, No. 1, pp. 73-97.

Quartz-Topp, J. Sanne, J and Postges, H. (2019). "Hybrid practices as a means to implement quality improvement: A comparative qualitative study in a Dutch and Swedish hospital”, Health Care Management Review, Vol. 43, No. 2, pp 148-156.

Richardson, S, and Asthana, S. (2006), "Inter-agency information sharing in Health and Social Care Services: The role of professional culture”, British Journal of Social Work, Vol. 36, pp. 657-669.

Shannon, C. and Weaver, W. (1949), The mathematical theory of communications, University of Illinois Press, Urbana.

Soda, G., Tortoriello, M. and Iorio, A. (2018), "Harvesting value from brokerage: Individual strategic orientation, structural holes, and performance," Academy of Management Journal, Vol. 61, No. 3, pp.896-918.

Spyridonidis, D. and Currie, G. (2016), “The Translational Role of Hybrid Nurse Middle Managers in Implementing Clinical Guidelines: Effect of, and upon, Professional and Managerial Hierarchies,” British Journal of Management, Vol. 27, pp. 760-777. doi:10.1111/1467-8551.12164.

Stake, R. (2005), Qualitative Case Studies. In N. K. Denzin \& Y. S. Lincoln (Eds.), The Sage handbook of qualitative research (pp. 443-466). Sage Publications Ltd, Thousand Oaks, CA.

Sy Diop, K. and Liu, E. (2020), "Categorization of case in case study research method: new approach", Knowledge and Performance Management, Vol. 4 No. 1, pp. 1-14. doi:10.21511/kpm.04(1).2020.01

The King's Fund (2018), “A year of integrated care systems: reviewing the journey so far”, The King's Fund, London. Available at: https://www.kingsfund.org.uk/sites/default/files/2018-09/Year-ofintegrated-care-systems-reviewing-the-journey-so-far-report-summary.pdf (accessed 20 December 2020).

Tritter, J. (2009), "Revolution or evolution: The challenges of conceptualising patient and public involvement in a consumerist world", Health Expect, Vol. 12, pp. 275-287.

Vargo, S.L. and Lusch, R.F. (2017), “Service-dominant logic 2025”, International Journal of Research in Marketing, Vol. 34, No. 1, pp.46-67.

Wait, S. and Nolte, E. (2006), "Public involvement policies in health: exploring their conceptual basis", Health Economic Policy Law, Vol. 1, pp. 149-162.

Waring, J., Currie, G., Crompton, A. and Bishop, S. (2013), “An exploratory study of knowledge 
brokering in hospital settings: Facilitating knowledge sharing and learning for patient safety?" Social Science \& Medicine, Vol. 98, pp. 79-86. doi.org/10.1016/j.socscimed.2013.08.037.

Wikner, J., Yang, B., Yang, Y. and Williams, S. (2017), "Decoupling thinking in service operations: a case in healthcare delivery system design," Production Planning \& Control, Vol. 28, pp. 387-397. doi:10.1080/09537287.2017.1298869.

Williams, S.J. and Radnor, Z. (2021). Moving from service to sustainable services: a healthcare case study, International Journal of Productivity and Performance Management, doi.org/10.1108/IJPPM12-2019-0583

Yin, R. (2014), Case Study Research: Design and Method ( $5^{\text {th }}$ ed), Sage Publications Ltd., Thousand Oaks, CA.

Table 1. Interview participants

\begin{tabular}{|c|c|c|}
\hline Participants & HD care network & COPD care network \\
\hline Healthcare practitioners & 5 & 20 \\
\hline Patients & 2 & 10 \\
\hline Care givers & 6 & 2 \\
\hline
\end{tabular}

Table 2. Inclusion and Exclusion criteria for the selection of research participants

\begin{tabular}{|c|c|}
\hline Inclusion criteria & Exclusion criteria \\
\hline Male or female & $\begin{array}{c}\text { Participants who are unable to consent for } \\
\text { themselves }\end{array}$ \\
\hline 18 years of age or older & \\
\hline Able to consent for themselves & \\
\hline $\begin{array}{c}\text { Caregiver or receiver (including } \\
\text { relatives/carer) for the selected conditions }\end{array}$ & \\
\hline $\begin{array}{c}\text { Health professional involved in providing } \\
\text { care within the selected care networks }\end{array}$ & \\
\hline
\end{tabular}

Table 3 Semi-structured Interview guide - patients and care givers

\begin{tabular}{|c|c|}
\hline Interview questions & Links to theory/framework \\
\hline $\begin{array}{l}\text { 1. When were you first diagnosed with your } \\
\text { condition? }\end{array}$ & $\begin{array}{l}\text { Experience and knowledge of } \\
\text { condition }\end{array}$ \\
\hline $\begin{array}{l}\text { 2. Can you describe your journey since you } \\
\text { were diagnosed? }\end{array}$ & $\begin{array}{l}\text { Understanding the research setting } \\
\text { Brokering and } \\
\text { knowledge/information sharing }\end{array}$ \\
\hline describe a typical day? & $\begin{array}{l}\text { Understanding the research setting } \\
\text { Brokering and } \\
\text { knowledge/information sharing }\end{array}$ \\
\hline $\begin{array}{l}\text { 4. Now how about a day when you have to } \\
\text { go to the clinic or hospital? }\end{array}$ & $\begin{array}{l}\text { Brokering and } \\
\text { knowledge/information sharing }\end{array}$ \\
\hline $\begin{array}{l}\text { 5. As you think about the journey since the } \\
\text { time you were diagnosed, what has gone }\end{array}$ & $\begin{array}{l}\text { Identify areas of good practice } \\
\text { including brokering and } \\
\text { knowledge/information sharing }\end{array}$ \\
\hline
\end{tabular}




\begin{tabular}{|c|c|}
\hline $\begin{array}{l}\text { well for you so far on this journey? Can } \\
\text { you give some examples? }\end{array}$ & \\
\hline $\begin{array}{l}\text { 6. What has not gone so well for you so far } \\
\text { on this pathway? Can you give some } \\
\text { examples? }\end{array}$ & $\begin{array}{l}\text { Identify areas for improvement } \\
\text { including brokering and } \\
\text { knowledge/information sharing }\end{array}$ \\
\hline $\begin{array}{l}\text { 7. Let me try to focus this a bit more: for the } \\
\text { things you do, are there things that could } \\
\text { be clearer, easier, or could work better? }\end{array}$ & $\begin{array}{l}\text { Identify areas for improvement } \\
\text { including } \\
\text { brokering and } \\
\text { knowledge/information sharing }\end{array}$ \\
\hline $\begin{array}{l}\text { 8. For the things the health professionals do, } \\
\text { are there things that could be clearer, } \\
\text { easier or could work better? Are there } \\
\text { some things you wish they knew more } \\
\text { about that are important to you? }\end{array}$ & $\begin{array}{l}\text { Identify areas for improvement } \\
\text { including brokering and } \\
\text { knowledge/information sharing }\end{array}$ \\
\hline $\begin{array}{l}\text { 9. For the concentrated work that you and } \\
\text { your health professionals do together, are } \\
\text { there things that could be clearer, easier, } \\
\text { or that could work better? }\end{array}$ & $\begin{array}{l}\text { Identify areas for improvement } \\
\text { including brokering and } \\
\text { knowledge/information sharing }\end{array}$ \\
\hline $\begin{array}{l}\text { 10. Is there anything else that you would like } \\
\text { to see improved? }\end{array}$ & $\begin{array}{l}\text { Identify areas for improvement } \\
\text { including brokering and } \\
\text { knowledge/information sharing }\end{array}$ \\
\hline $\begin{array}{l}\text { 11. What information have you received } \\
\text { about the journey/your condition? }\end{array}$ & $\begin{array}{l}\text { Brokering and } \\
\text { knowledge/information sharing }\end{array}$ \\
\hline $\begin{array}{l}\text { 12. In what ways was the information helpful } \\
\text { to you? To those others in your family or } \\
\text { the others who support you? }\end{array}$ & $\begin{array}{l}\text { Brokering and } \\
\text { knowledge/information sharing }\end{array}$ \\
\hline 13. Could the information be improved? & $\begin{array}{l}\text { Identify areas for improvement } \\
\text { including brokering and } \\
\text { knowledge/information sharing }\end{array}$ \\
\hline $\begin{array}{l}\text { 14. Would you like to add any additional } \\
\text { points or stress anything in particular? }\end{array}$ & \\
\hline
\end{tabular}




\section{Boundaries}

\begin{tabular}{|c|c|c|c|}
\hline \multirow{2}{*}{$\begin{array}{ll}\stackrel{+}{C} & \\
\stackrel{Q}{E} & \text { Relational property } \\
\searrow & \text { of knowledge }\end{array}$} & Syntactic & Semantic & Pragmatic \\
\hline & $\begin{array}{l}\text { Actors share } \\
\text { common } \\
\text { knowledge and } \\
\text { lexicon }\end{array}$ & $\begin{array}{l}\text { Actors negotiate } \\
\text { and alter the } \\
\text { knowledge interest } \\
\text { from their domain }\end{array}$ & $\begin{array}{l}\text { Actors develop } \\
\text { common interests } \\
\text { to provide a means } \\
\text { of sharing and } \\
\text { assessing } \\
\text { knowledge }\end{array}$ \\
\hline Broker capability & $\begin{array}{l}\text { Information and } \\
\text { knowledge transfer }\end{array}$ & $\begin{array}{l}\text { Translating } \\
\text { knowledge to } \\
\text { create shared } \\
\text { meaning }\end{array}$ & $\begin{array}{l}\text { Transforming } \\
\text { knowledge to } \\
\text { create common } \\
\text { interests and } \\
\text { assess knowledge }\end{array}$ \\
\hline
\end{tabular}

Figure 1: Knowledge boundary management

Figure 2. Case study design

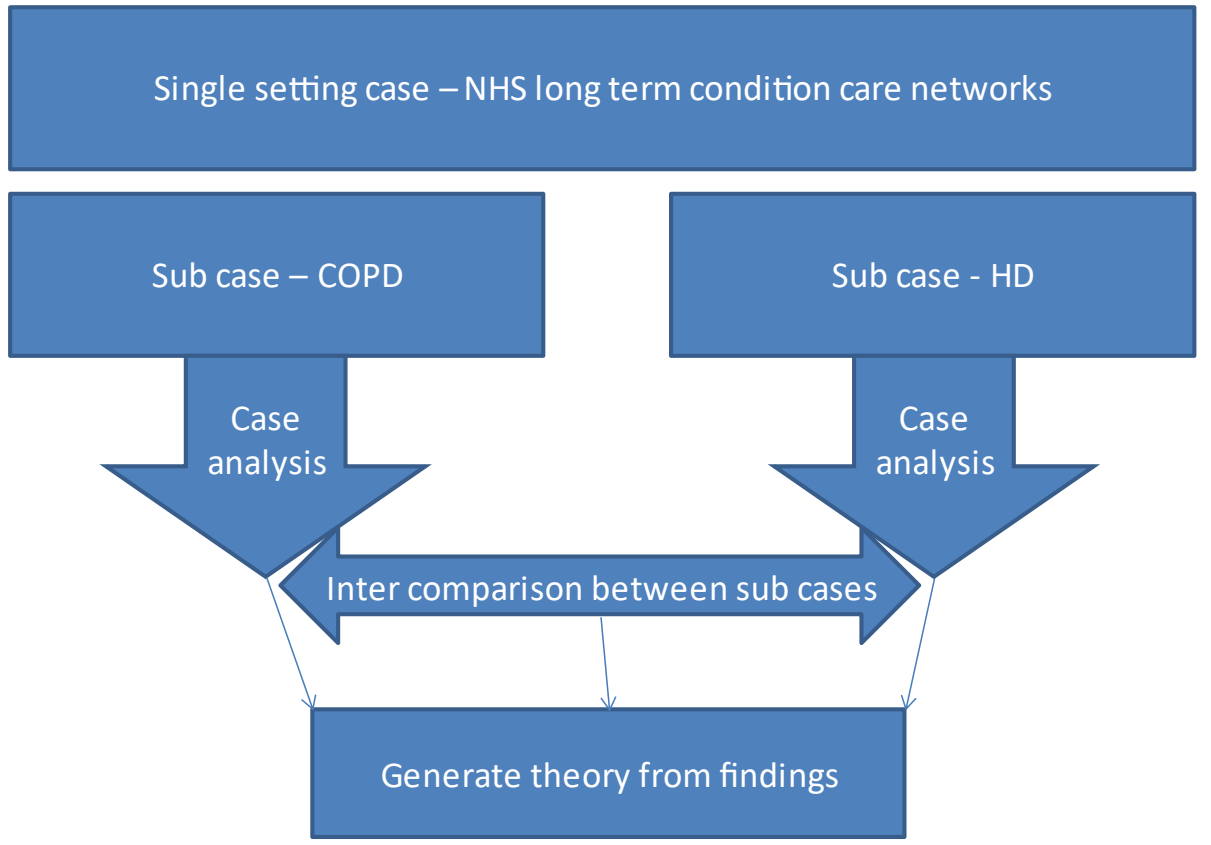

Adapted from Sy Diop and Liu (2020) 
Figure 3. Actors involved in the two care networks

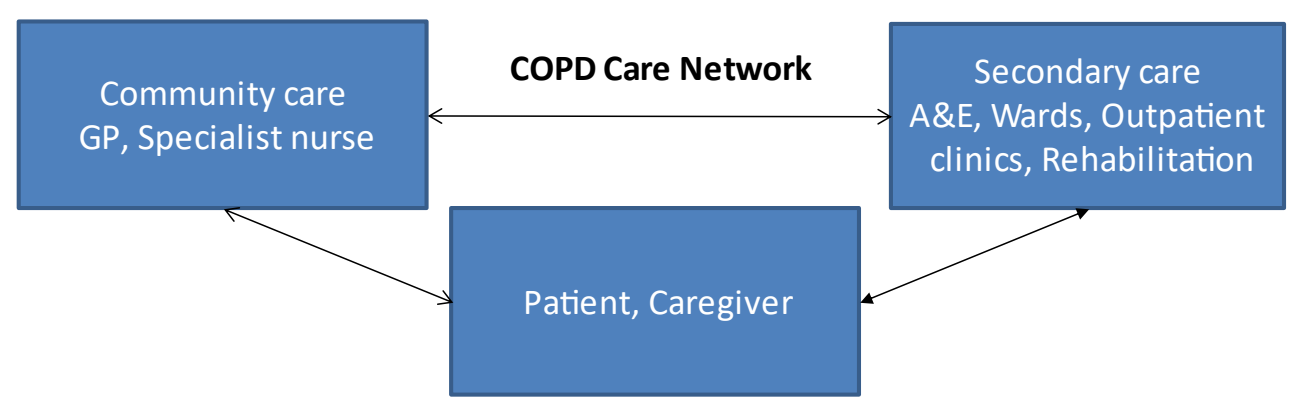

\section{HD Care Network}

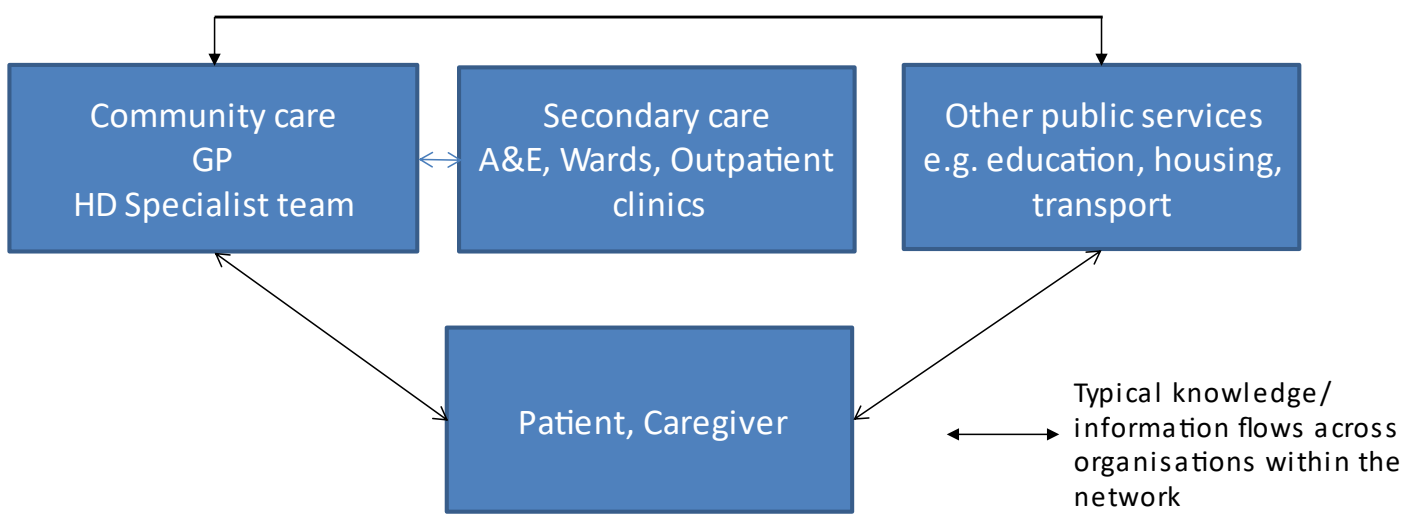

Figure 4. Coding framework

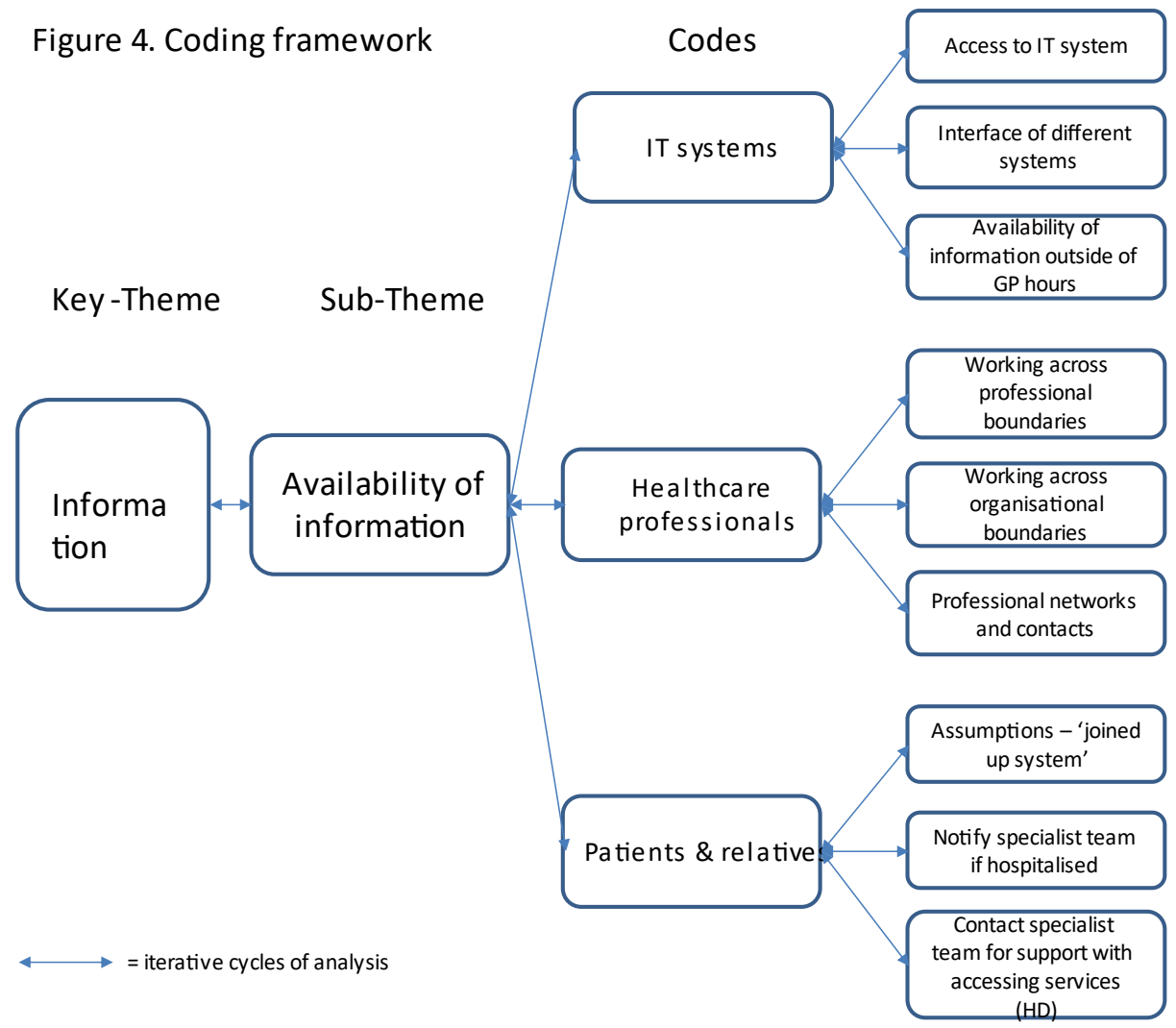

Sub-codes 